\title{
Immunohistochemical analysis of human arrest-defective-1 expressed in cancers in vivo
}

\author{
MIN YU ${ }^{1 *}$, JUNLI GONG $^{1 *}$, MINGXING MA $^{1}$, HUI YANG ${ }^{2}$, JIANHUA LAI $^{1}$, \\ HONG WU ${ }^{1}$, LIN LI ${ }^{2}$, LAMEI LI ${ }^{1}$ and DEYONG TAN ${ }^{1}$ \\ ${ }^{1}$ Laboratory of Biochemistry and Molecular Biology, School of Life Science, Yunnan University, 650091 Kunming; \\ ${ }^{2}$ Department of Pathology, First People's Hospital of Yunnan Province, 650032 Kunming, P.R. China
}

Received October 14, 2008; Accepted December 8, 2008

DOI: $10.3892 /$ or_00000303

\begin{abstract}
The arrest-defective-1 (ARD1) gene has been reported to be important in yeast cell cycle regulation, and recent studies have shown that human arrest-defective-1 (hARD1) is related to cancer cell proliferation. To investigate the expression pattern of hARD1 protein in cancer tissues, immunohistochemical analysis was performed to analyze the hARD1 expression pattern in 400 cases of 19 types of common cancer and 133 non-cancer samples from 11 tissue types. hARD1 protein was expressed extensively in cancer tissues including glandular carcinoma and squamous cancer, and the positive rate was $71.5 \%(15 / 20)$ in urinary bladder cancer, $62.5 \%(30 / 48)$ in breast cancer and $57.1 \%(8 / 14)$ in cervical carcinoma. The average hARD1-positive rate was $52.3 \%$ in cancers and $31.5 \%$ in non-cancers, for which the difference was significant $(\mathrm{p}<0.005)$. Comparing the staining intensity of different fields in the same section, the hARD1 protein was highly accumulated in cancer cells when compared to the cells adjacent to cancer. The positive rate of breast and intestinal cancer was obviously higher than corresponding non-cancers $(\mathrm{p}<0.05$ and 0.01$)$. These findings suggest that the accumulation of hARD1 protein may be related to carcinogenesis of various types of cancer.
\end{abstract}

\section{Introduction}

The ARD1 (arrest-defective-1) gene encodes an N-acetyltransferase. It binds with Nat1 and forms a complex for catalyzing the acetylation of proteins at both $\alpha$-(N-terminus) and $\varepsilon$-amino groups $(1,2)$. It was first cloned in Saccharomyces

Correspondence to: Dr DeYong Tan, Laboratory of Biochemistry and Molecular Biology, School of Life Science, Yunnan University, 650091 Kunming, P.R. China

E-mail: dytan@ynu.edu.cn

${ }^{*}$ Contributed equally

Key words: human arrest-defective-1 protein, immunohistochemical analysis, cancer tissues cerevisiae (3), then in human and other mammalian cells $(4,5)$.

Although ARD1 has been identified as an N-acetyltransferase, its physiological significance is not yet clear. In Saccharomyces cerevisiae, ARD1 mutations lead to the inability to respond to $\alpha$-factor, to enter stationary phase and to sporulate, suggesting an important role for the ARD1 gene product in controlling the switch between the mitotic cell cycle and alternative cell fates (3). Analysis of cell typespecific gene expression demonstrated that the hARD1 gene encodes a protein product that acts, directly or indirectly, at the HML locus to repress its expression and, by analogy, may control expression of other genes involved in monitoring nutritional conditions (6). In mammalian cells, a contrary opinion regarding ARD1 regulation of hypoxia inducible factor-1 $\alpha(\mathrm{HIF}-1 \alpha)$ was reported recently $(3,7-11)$. Several reports proposed that hARD1-mediated acetylation of hypoxia-inducible factor $1 \alpha$ subunit (HIF-1 $\alpha$ ) enhances the interaction of HIF- $1 \alpha$ with pVHL and HIF- $1 \alpha$ ubiquitination, which promotes the destabilization of HIF- $1 \alpha$ with proteasomal degradation $(7,8)$. However, other reports proposed that the hARD1 expression level did not result in HIF-1 destablization $(2,9,11)$. hARD1 short hairpin RNA delivered by a retroviral vector caused $>80 \%$ reduction in hARD1 message RNA. It also caused decreases in the erythropoietin and vascular endothelial growth factor protein production, whereas there was no change in the HIF-1 $\alpha$ protein level (9). hARD1 does not acetylate and destabilize HIF-1 $\alpha$ although hARD1 specifically binds HIF-1 $\alpha$ (2). The hARD1 mRNA and protein levels were not regulated by hypoxia in several human tumor cell lines. In wild-type and HIF-1-null mouse embryo fibroblasts and HeLa cells silenced for HIF-1 or -2 by RNA interference, the level of expression of the hARD1 protein was independent of HIF-1 and -2 , and hARD1 is a stable, predominantly cytoplasmic protein expressed in a broad range of tissues (11).

There are several clues indicating the relationship between the hARD1 gene and carcinogenesis. In yeast, ARD1 acts as a cell cycle regulation gene $(3,6)$. Comparing the expressional level of the gene in moderately differentiated hepatocellular carcinoma (MD) with well-differentiated hepatocellular carcinoma (b), hARD1 gene expression was significantly elevated (12). N-acetyl-transferase human (NATH) is 
Table I. The hARD1 expression rate in cancer and non-cancer tissues.

\begin{tabular}{|c|c|c|c|c|c|c|c|}
\hline \multirow[b]{2}{*}{ Tissue origin } & \multicolumn{3}{|c|}{ Cancer samples } & \multicolumn{3}{|c|}{ Non-cancer samples } & \multirow[b]{2}{*}{ P-value } \\
\hline & Samples (n) & Positive samples & Positive rate $(\%)$ & Samples (n) & Positive samples & Positive rate $(\%)$ & \\
\hline Urinary bladder & 21 & 15 & 71.4 & 2 & 1 & 0.5 & $\mathrm{~N}$ \\
\hline Breast & 48 & 30 & 62.5 & 21 & 8 & 38.1 & $<0.050$ \\
\hline Cervix & 14 & 9 & 64.2 & 14 & 5 & 35.7 & $\mathrm{~N}$ \\
\hline Hypothyroid & 12 & 9 & 75.0 & 5 & 2 & 28.5 & $\mathrm{~N}$ \\
\hline Stomach & 56 & 30 & 53.6 & 19 & 10 & 47.3 & $\mathrm{~N}$ \\
\hline Lung & 29 & 16 & 55.2 & 3 & 1 & 33.3 & $\mathrm{~N}$ \\
\hline Colorectum & 125 & 60 & 48.0 & 22 & 4 & 18.2 & $<0.010$ \\
\hline Prostate & 12 & 7 & 58.3 & 5 & 2 & 0.4 & $\mathrm{~N}$ \\
\hline Nasopharynx & 11 & 6 & 54.5 & 15 & 3 & 0.2 & $<0.100$ \\
\hline Liver & 9 & 3 & 33.3 & 1 & 0 & 0.0 & $\mathrm{~N}$ \\
\hline Oesophagus & 19 & 6 & 31.5 & - & - & - & $\mathrm{N}$ \\
\hline Skin & 14 & 3 & 21.4 & 2 & 1 & - & - \\
\hline Kidney & 10 & 5 & 50.0 & 4 & 0 & 20.0 & $<0.100$ \\
\hline Gallbladder & 4 & 0 & 0.0 & 15 & 5 & 33.3 & $\mathrm{~N}$ \\
\hline Eye & 3 & 1 & 33.3 & - & - & - & - \\
\hline Vocal cords & 5 & 3 & 60.0 & 4 & 0 & 0.0 & $<0.100$ \\
\hline Pancreas & 2 & 1 & 50.0 & 1 & 0 & 0.0 & $\mathrm{~N}$ \\
\hline Ovary & 3 & 3 & 100.0 & - & - & - & - \\
\hline Brain & 3 & 2 & 66.7 & - & - & - & - \\
\hline Total & 400 & 209 & 52.3 & 133 & 42 & 31.5 & $<0.005$ \\
\hline
\end{tabular}

overexpressed at the mRNA level in papillary thyroid carcinomas relative to non-neoplastic thyroid tissue (2). Since NATH protein is the partner of hARD1 and this complex acetylates the N-termini of proteins, hARD1 may also be related to papillary thyroid carcinoma. Other reports proposed that hADR 1 acetylates and activates B-catenin and promotes lung cancer cell proliferation (14). However, there is no direct evidence for the relationship between the hARD1 gene and cancer.

Analysis of the gene expression pattern contributes to the elucidation of tumor-related genes. In this study, we analyzed the hARD1 protein level in a number of common cancer types in order to investigate the expression pattern of hARD1 in cancers in vivo thus exploring the relationship between hARD1 and cancer.

\section{Materials and methods}

Sample collection. In this study, samples from 400 malignant cancer cases from 19 tissue types and 133 samples from noncancer cases from 11 tissue types (Table I) were collected. All samples were obtained from surgical tissue of anonymous patients (age range 35-80, average age 50.5). The cancer samples were primary cancer tissues of patients who had no previous history of any form of malignancy and had not previously received radiotherapy or chemotherapy. Pathological evaluation was conducted through clinical diagnosis (Hui Yang, Lin Li). As informed patient consent was not provided for these samples, identifying information for all samples was removed before analysis. This procedure conformed to the consensus statement on use of archival samples (13).

Western blot analysis. Protein extracts were prepared by homogenizing $0.2 \mathrm{~g}$ of frozen tissue in $1 \mathrm{ml}$ of protein extract solution $(20 \mathrm{mM}$ Tris-HCl, $1 \mathrm{mM}$ EDTA, $150 \mathrm{mM}$ $\mathrm{NaCl}, 1 \%$ Triton $\mathrm{X}-100$ and $1 \mathrm{mM}$ PMSF) and by incubating for $30 \mathrm{~min}$ at $4^{\circ} \mathrm{C}$. After centrifugation at $10,000 \times \mathrm{g}$ for $20 \mathrm{~min}$ at $4^{\circ} \mathrm{C}$, the supernatant was collected, and an equal volume of $2 \mathrm{X}$ loading buffer was added $(100 \mathrm{mM}$ Tris- $\mathrm{HCl}$ pH 6.8, 250 mM DTT, 4\% SDS, $0.2 \%$ bromophenol blue and $20 \%$ glycerol), boiled for $10 \mathrm{~min}$, and loaded onto $10 \%$ SDSpolyacrylamide gels. Proteins were transferred onto nitrocellulose membranes by the Semi-dry Transfer Electrophoresis apparatus (Bio-Rad). Western blotting was performed with Vectastain $^{\circledR}$ ABC-AmP ${ }^{\mathrm{TM}}$ Western Blotting Chromogenic Detection Kit AK-6402 (Vector Laboratories), according to the manufacturer's protocol. The anti-hARD1 monoclonal antibody (Abnova) was diluted 1:1000.

Immunohistochemistry. Fresh patient tissues were cut into $1-\mathrm{cm}^{3}$ blocks and fixed in formaldehyde for 2 days, dehydrated in graded ethanol solutions for $30 \mathrm{~min}$, immersed in xylene for $30 \mathrm{~min}$, and embedded in paraffin. Immunohistochemical assays were performed on $10-\mu \mathrm{m}$ paraffin sections using the SP Kit (Maixin-bio) according to the manufacturer's protocol. Briefly, tissue sections were treated with peroxide $(10 \mathrm{mg} / \mathrm{ml})$ for $10 \mathrm{~min}$ at $\mathrm{RT}$, washed $3 \times 3 \mathrm{~min}$ with PBS, and incubated in $5 \%$ bovine serum for $10 \mathrm{~min}$ at RT. Slides were then incubated with anti-hARD1 mono- 

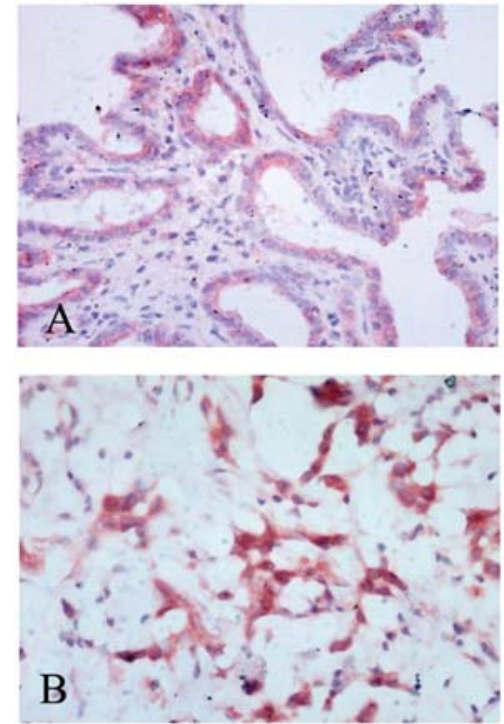

hARD1

$(26 \mathrm{kDa})$

Figure 1. The specificity of hARD1 immunohistochemical staining. (A and B) hARD1-positive immunohistochemical samples. (C) Western blot detection of hARD1 in tissues A and B.

clonal antibody (1:200) for $1 \mathrm{~h}$ at $37^{\circ} \mathrm{C}$, washed $3 \times 5$ min with PBS, incubated with biotinylated anti-mouse IgG for $10 \mathrm{~min}$ at RT, and then washed $3 \times 5$ min with PBS. Slides were then incubated in streptavidin coupled to horseradish peroxidase for 10 min at RT and washed 3 x 3 min with PBS. Staining was performed with diaminobenzidine (DAB) solution for $5 \mathrm{~min}$, and slides were then rinsed with water to stop the reaction. Negative controls were performed by replacing the primary antibody with PBS.
Slides were stained in haematoxylin for $1 \mathrm{~min}$. The semiquantitative analysis of hARD1 protein levels was scored independently by two trained pathologists (L.L. and H.Y.) and calibrated to a modified immunohistochemical scoring system as described $(14,15)$. Cells $(\sim 500)$ from five high magnification fields were evaluated for staining intensity [SI: 0 , negative; 1 , weak (buff yellow); 2 , intermediate (brown yellow) and 3 , strong (brown)] and the percentage of total immunoreactive cells (PS: 0-100\%). For each sample, hARD1 protein levels (L) were evaluated as the sum of each SI and corresponding PS. Finally, an ARD1 protein index was scored from 1 to 4 : index 1 , negative (16), index 2, low positive $(0 \leq \mathrm{L}<0.5)$, index 3 , positive $(0.5 \leq \mathrm{L}<2)$, and index 4 , very highly positive $(2 \leq \mathrm{L} \leq 3)$. The positive rate equaled the total number of positive samples (including low positive, positive and very high positive) divided by the total samples. The association of staining patterns with clinicopathological features was assessed with the $\chi^{2}$ test.

\section{Results}

Specificity of the hARDl antibody was confirmed by immunohistochemistry. Two hARD1 immunohistochemically positive samples were assayed by Western blot analysis. Each sample showed a single band of hARD1 protein (Fig. 1C), which indicated that the anti-hARD1 antibody recognized the hARD1 protein specifically.

hARDI was expressed at a high rate in cancer tissues. The hARD1 protein level was detected through immunohistochemical analysis in 19 common types of cancers (Table I). hARD1 was expressed in almost all types of examined

Table II. The hARD1 expression pattern in glandular carcinoma and squamous cancer.

\begin{tabular}{|c|c|c|c|c|c|c|}
\hline \multirow[b]{2}{*}{ Tissue origin } & \multicolumn{3}{|c|}{ Glandular carcinoma } & \multicolumn{3}{|c|}{ Squamous cancer } \\
\hline & Samples (n) & Positive samples & Positive rate $(\%)$ & Samples (n) & Positive samples & Positive rate $(\%)$ \\
\hline Breast & 48 & 30 & 62.5 & 0 & 0 & - \\
\hline Cervix & 5 & 3 & 60.0 & 9 & 5 & 55.6 \\
\hline Stomach & 50 & 27 & 54.0 & 6 & 3 & 50.0 \\
\hline Lung & 15 & 10 & 66.7 & 11 & 5 & 45.5 \\
\hline Colorectum & 125 & 60 & 48.0 & 0 & 0 & - \\
\hline Prostate & 12 & 7 & 58.3 & 0 & 0 & - \\
\hline Nasopharynx & 0 & 0 & - & 7 & 3 & 42.9 \\
\hline Liver & 1 & 1 & 100.0 & 0 & 0 & - \\
\hline Oesophagus & 2 & 0 & 0.0 & 17 & 6 & 35.3 \\
\hline Skin & 1 & 0 & 0.0 & 9 & 1 & 11.0 \\
\hline Kidney & 5 & 1 & 20.0 & 0 & 0 & - \\
\hline Gallbladder & 2 & 0 & 0.0 & 0 & 0 & - \\
\hline Vocal cords & 0 & 0 & - & 5 & 3 & 60.0 \\
\hline Pancreas & 2 & 1 & 50.0 & 0 & 0 & - \\
\hline Ovary & 3 & 3 & 100.0 & 0 & 0 & - \\
\hline Brain & 1 & 1 & 100.0 & 0 & 0 & - \\
\hline Total $^{\mathrm{a}}$ & 272 & 144 & 52.9 & 64 & 26 & 40.6 \\
\hline
\end{tabular}

${ }^{a} \chi^{2}$ value between glandular carcinoma and squamous cancer was 3.11 and the significant difference was $\mathrm{p}<0.1$. 


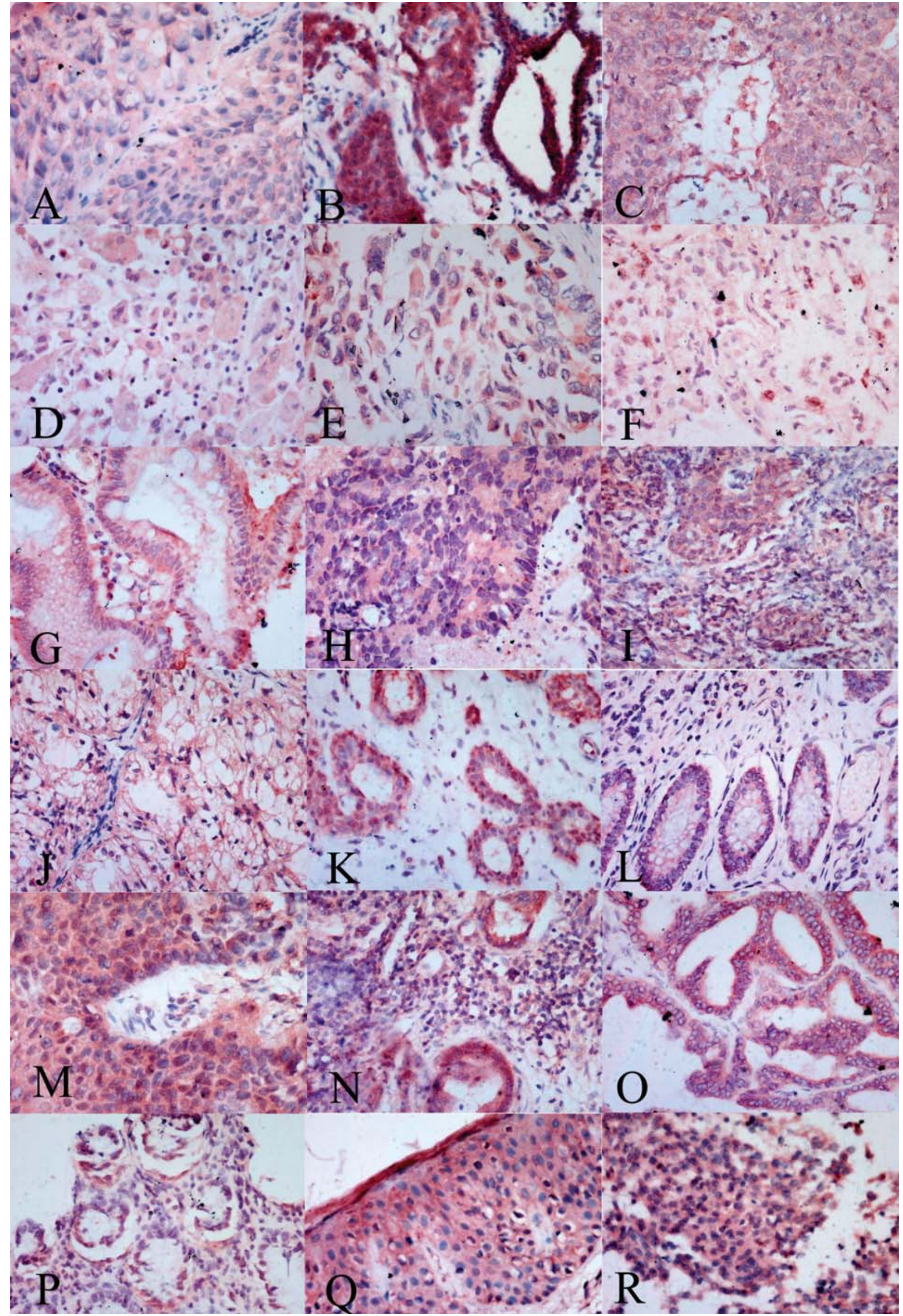

Figure 2. hARD1 was expressed in various types of cancer tissues: (A) urinary bladder, (B) breast, (C) cervical, (D) hypothyroid, (E) stomach, (F) lung and $(\mathrm{G})$ rectal cancers, $(\mathrm{H})$ colon carcinoma, (I) prostate, $(\mathrm{J})$ nasopharyngeal and $(\mathrm{K})$ kidney cancers, $(\mathrm{L})$ hepatoma, $(\mathrm{M})$ vocal cord, $(\mathrm{N})$ pancreatic, $(\mathrm{O})$ ovarian and $(\mathrm{P})$ oesophageal cancers, $(\mathrm{Q})$ cutaneous tumor and $(\mathrm{R})$ brain tumor. 


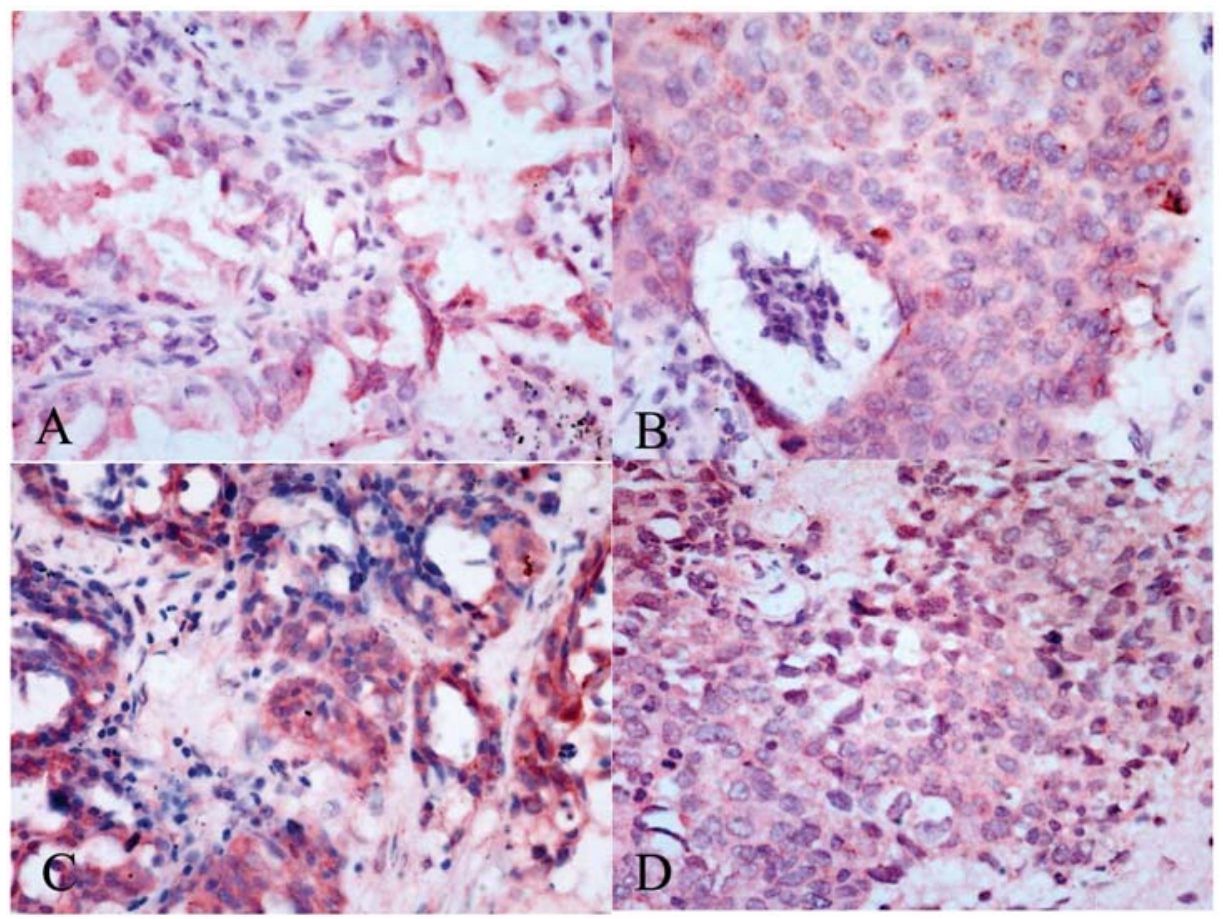

Figure 3. hARD1 was expressed in glandular epithelium and squamous epithelium cancers. (A) Adenocarcinoma of the lung, (B) squamous cancer of the lung, (C) endometrioid adenocarcinoma and (D) cervical squamous cancer.

cancers including urinary bladder, breast, cervical, hypothyroid, stomach, lung and rectum cancers, colon carcinoma, prostate, nasopharynx and kidney cancers, hepatoma, vocal cord, pancreatic, ovarian and oesophageal cancers and cutaneous and brain tumors (Fig. 2). The hARD1 staining signal was strongest in epithelia, and weaker in other cells. Since most cancers originate in glandular epithelium and squamous epithelium, we compared the difference in hARD1 expression between adenocarcinoma and squamous cancer. The results showed that both adenocarcinoma and squamous cancer expressed hARD1 protein, and the positive rate was lower in glandular carcinoma than squamous cancer (Table II). An hARD1 strong staining signal also appeared in both glandular carcinoma and squamous cancer of the same tissue type (Fig. 3).

Comparing the hARD1 expression rate among different types of cancers (Table I), high hARD1 expression was found in breast cancer $(62.5 \%, 30 / 48)$, urinary bladder cancer $(71.4 \%, 15 / 21)$, stomach carcinoma $(53.6 \%, 30 / 56)$, cervical carcinoma $(64.2 \%, 9 / 14)$, hypothyroid carcinoma $(75 \%$, $9 / 11)$, lung cancer $(55.2 \%, 16 / 29)$ and intestinal cancer $(48 \%$ $60 / 125)$. The average positive rate of the 400 samples was $52.3 \%(209 / 400)$.

Correlation of hARD1 to cancers. We examined the hARD1 level of adjacent tissues and cancer tissues in the same tissue section and discovered that the hARD1 level was lower in the adjacent tissues compared to the corresponding cancer tissues (Fig. 4). In order to compare the hARD1 protein level between cancer tissues and non-cancer tissues, 133 samples of 11 types of non-cancer tissues, which including inflamed, hyperplasy and polypus tissues, were screened. The average positive rate of hARD1 was only $31.5 \%$, and there was a significant difference between cancer and non-cancer (Table I). The difference in the hARD1-positive rate between cancer and the corresponding non-cancer tissue was significant in breast tissue $(\mathrm{p}<0.05)$, colorectal tissue $(\mathrm{p}<0.01)$ and nasopharyngeal tissue $(\mathrm{p}<0.1)$.

\section{Discussion}

In order to identify the specificity of immunohistochemical staining, Western blot analysis was used to detect hARD1 expression in the tissues. Two sample extracts showed the same 26-kDa single band of the hARD1 protein (Fig. 1C). The corresponding immunohistochemical images showed that the hARD1 staining signal was detected only in cancer cells (Fig. 1A and B). In the single cell, hARD1 staining was in both the cytoplasm and nucleus, which was consistent with a previous report (2). These results suggest the specificity of hARD1 by immunohistochemistry.

In this study, we screened 19 types of cancers (Table I) and most accumulated a high level of hARD1 protein. Since these cancers are common types of cancer, the results suggest that expression of hARD1 is widespread in cancers (Fig. 2). Most types of cancers originate in epithelial cells including glandular and squamous epithelium. Expression of hARD1 was accumulated in adenocarcinoma and squamous cancer. Even in the same type of cancer, hARD1 was accumulated both in adenocarcinoma and squamous cancer (Fig. 3).

Uncontrolled proliferation and a lack of apoptosis are the basic characteristics of cancer cells. The role of hARD1 has been reported to be involved in cellular proliferation in hepatocarcinoma HepG2 cells (9) and lung cancer cell lines (17). These results strongly imply the importance of hARD1 in cancer development, and encouraged us to examine the 


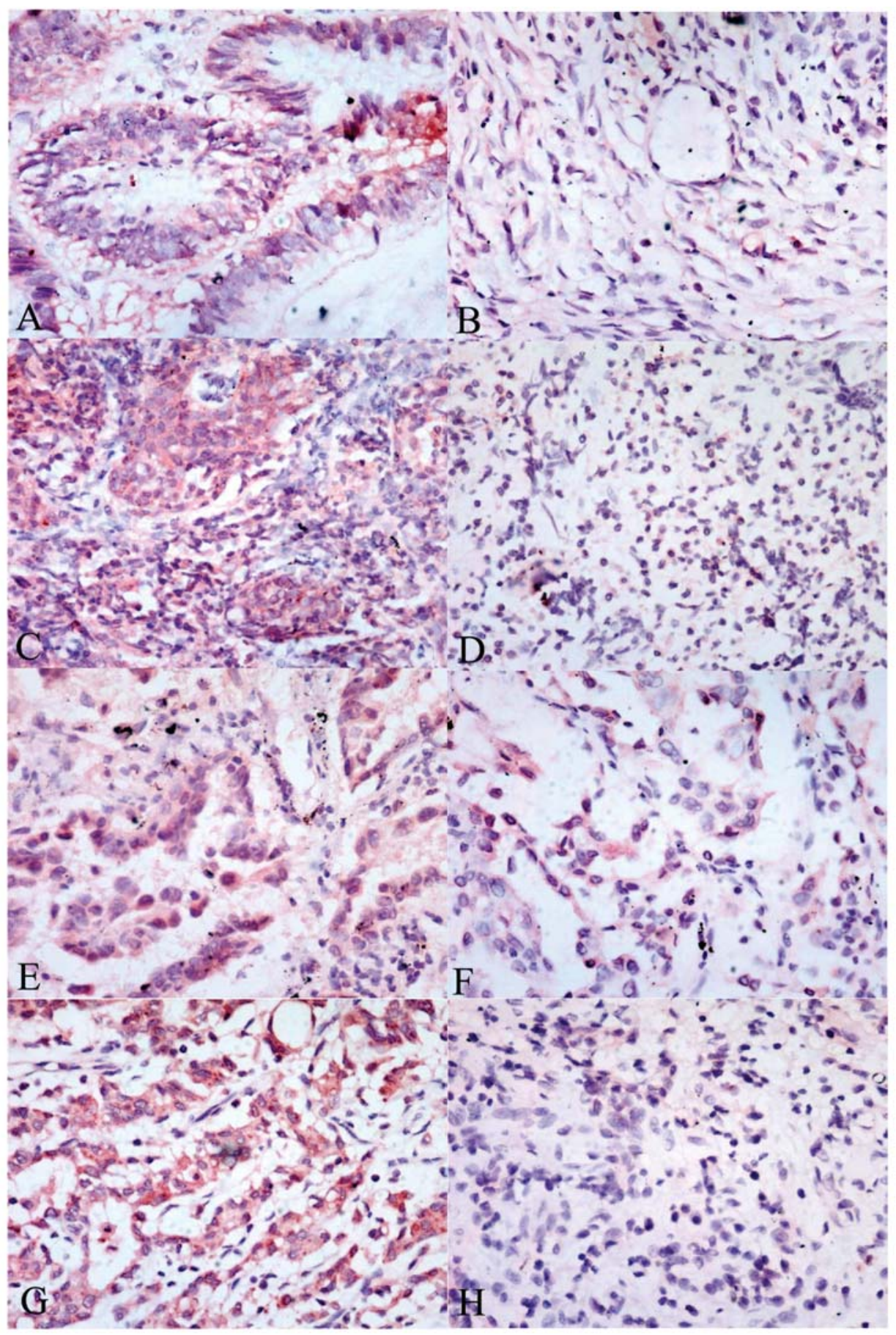

Figure 4. Comparison of the hARD1 expression level in cancer tissue with corresponding adjacent tissue in the same section. (A) Intestinal adenocarcinoma, (B) adjacent tissue corresponding to sample A, (C) pharynx nasalis squamous cancer, (D) adjacent tissue corresponding to sample C, (E) lung squamous cancer, $(\mathrm{F})$ adjacent tissue corresponding to sample $\mathrm{E},(\mathrm{G})$ poorly differentiated stomach adenocarcinoma, $(\mathrm{H})$ adjacent tissue corresponding to sample $\mathrm{G}$.

hARD1 protein expression pattern in various cancer tissues. In this study, we found that hARD1 was expressed more strongly in cancer than non-cancer tissues. Interestingly, the hARD1 staining signal was stronger in cancer compared to tissues adjacent to cancer. Since the numbers of samples of breast tissue and colorectal tissue were large enough for statistical analysis, the $\chi^{2}$ test was performed and the difference between cancer and non-cancer was significant in both types of cancer. These results indicate that hARD1 is related to carcinogenesis.

Previous in vitro investigations showed that hARD1 was expressed in hepatocellular carcinoma and thyroid neoplasms and was related to the differentiation of cancer cells $(11,12)$, and also promoted lung cancer cell proliferation (17). In the present study, we confirmed the hARD1 expression pattern in cancer tissues in vivo and the correlation with cancers primarily, establishing a base for further functional studies of hARD1.

Acetylation and deactylation are also important posttranslational modifications (18) and regulation of protein activation (19), which is related to leukemia and other diseases. hARD1 acts as an acetyltransferase for non-histone acetylation. The present investigation showed the relationship 
between the expression level of hARD1 and cancers, which further suggests that acetylation is related to carcinogenesis.

In conclusion, according to immunohistochemistry, hARD1 is extensively expressed in various types of cancers and is involved in carcinogenesis.

\section{Acknowledgements}

We are grateful to the Department of Pathology, First People's Hospital of Yunnan Province for providing the patient tissue samples. This work was made possible by generous support from the National Natural Science Foundation of China (nos. $30360040,30760057)$ and the Science and Technological Key Project of Yunnan Province (no. 2006SG09).

\section{References}

1. Polevoda B, Norbeck J, Takakura H, Blomberg A and Sherman F Identification and specificities of N-terminal acetyltransferases from Saccharomyces cerevisiae. EMBO J 18: 6155-6168, 1999.

2. Arnesen T, Anderson D, Baldersheim C, Lanotte M, Varhaug JE and Lillehaug JR: Identification and characterization of the human ARD1-NATH protein acetyltransferase complex. Biochem J 386: 433-443, 2005.

3. Whiteway M and Szostak JW: The ARD1 gene of yeast functions in the switch between the mitotic cell cycle and alternative developmental pathways. Cell 43: 483-492, 1985.

4. Tribioli C, Mancini M, Plassart E, Bione S, Rivella S, et al: Isolation of new genes in distal Xq28: transcriptional map and identification of a human homologue of the ARD1 N-acetyl transferase of Saccharomyces cerevisiae. Hum Mol Genet 3: 1061-1067, 1994.

5. Kim SH, Park JA, Kim JH, Lee JW, Seo JH, et al: Characterization of ARD1 variants in mammalian cells. Biochem Biophys Res Commun 340: 422-427, 2006.

6. Whiteway M, Freedman R, Van Arsdell S, Szostak JW and Thorner J: The yeast ARD1 gene product is required for repression of cryptic mating-type information at the HML locus. Mol Cell Biol 7: 3713-3722, 1987.
7. Jeong JW, Bae MK, Ahn MY, Kim SH, Sohn TK, et al: Regulation and destabilization of HIF-1alpha by ARD1-mediated acetylation. Cell 111: 709-720, 2002.

8. Lee KH, Choi E, Chun YS, Kim MS and Park JW: Differential responses of two degradation domains of HIF-1alpha to hypoxia and iron deficiency. Biochimie 88: 163-169, 2006.

9. Fisher TS, Etages SD, Hayes L, Crimin K and Li B: Analysis of ARD1 function in hypoxia response using retroviral RNA interference. J Biol Chem 280: 17749-17757, 2005.

10. Arnesen T, Kong X, Evjenth R, Gromyko D, Varhaug JE, et al: Interaction between HIF-1 alpha (ODD) and hARD1 does not induce acetylation and destabilization of HIF-1 alpha. FEBS Lett 579: 6428-6432, 2005.

11. Bilton R, Mazure N, Trottier E, Hattab M, Dery MA, et al: Arrest-defective-1 protein, an acetyltransferase, does not alter stability of hypoxia-inducible factor (HIF)-1alpha and is not induced by hypoxia or HIF. J Biol Chem 280: 31132-31140, 2005.

12. Midorikawa Y, Tsutsumi S, Taniguchi H, Ishii M, Kobune Y, et al: Identification of genes associated with dedifferentiation of hepatocellular carcinoma with expression profiling analysis. Jpn J Cancer Res 93: 636-643, 2002.

13. Clayton EW, Steinberg KK, Khoury MJ, Thomson E, Andrews L, et al: Informed consent for genetic research on stored tissue samples. JAMA 274: 1786-1792, 1995.

14. Bosman FT, de Goeij AF and Rousch M: Quality control in immunocytochemistry: experiences with the oestrogen receptor assay. J Clin Pathol 45: 120-124, 1992.

15. Rau B, Sturm I, Lage H, Berger S, Schneider U, et al: Dynamic expression profile of $\mathrm{p} 21 \mathrm{WAF} 1 / \mathrm{CIP} 1$ and $\mathrm{Ki}-67$ predicts survival in rectal carcinoma treated with preoperative radiochemotherapy. J Clin Oncol 21: 3391-3401, 2003.

16. Aragona M, Panetta S, Silipigni AM, Romeo DL, Pastura G, et al: Nerve growth factor receptor immunoreactivity in breast cancer patients. Cancer Invest 19: 692-697, 2001.

17. Lim JH, Park JW and Chun YS: Human arrest defective 1 acetylates and activates beta-catenin, promoting lung cancer cell proliferation. Cancer Res 66: 10677-10682, 2006.

18. Yang XJ: The diverse superfamily of lysine acetyltransferases and their roles in leukemia and other diseases. Nucleic Acids Res 32: 959-976, 2004.

19. Boyes J, Byfield P, Nakatani Y and Ogryzko V: Regulation of activity of the transcription factor GATA-1 by acetylation. Nature 396: 594-598, 1998. 